\title{
Design and Optimized Application of Online Financial Management System Based on Internet of Things
}

\author{
Jia Li iD \\ Hebei Chemical \& Pharmaceutical College, Shijiazhuang 050026, China \\ Correspondence should be addressed to Jia Li; hebcpc@st.btbu.edu.cn
}

Received 22 November 2021; Revised 26 December 2021; Accepted 13 January 2022; Published 8 February 2022

Academic Editor: Sikandar Ali

Copyright (c) 2022 Jia Li. This is an open access article distributed under the Creative Commons Attribution License, which permits unrestricted use, distribution, and reproduction in any medium, provided the original work is properly cited.

\begin{abstract}
With the rapid development of science and technology, the requirements for the use of financial management systems required by users are also constantly improving; therefore, the financial management system is updated rapidly, and a single financial management mode can no longer meet the needs of users' development. Designing a management system integrating business and finance can effectively maintain the stability of user's (enterprises) development. Besides, all aspects of the designed system should be carefully divided and upgraded to adapt to the complex internal operation mode of some enterprise users. This article is mainly based on the use of Internet of Things technology to design a more optimized online financial management system so that its users can have more convenient and accurate access to or processing of certain information. This is to build an online financial management system based on the blockchain technology of the Internet of Things, complex network information transmission detection technology, and multiplexed information transmission technology and to expand the application scope of its functions by building databases, financial information systems, and financial analysis systems. By comparing and analyzing the system constructed in this article with the system proposed by Zhang Yuzhuo earlier, which is suitable for the strategic integration development of his enterprise, we can find that this system has advantages in reliability, simultaneity, and delay, that is, data transmission efficiency. This shows that the online financial management system designed in this paper can be carried out normally in actual activities and has certain advantages.
\end{abstract}

\section{Introduction}

With the progress of society, people's living standards are constantly improving. The convenience brought by the Internet of Things promotes many business models to change from a single offline activity to a combination of online and offline. This business model undoubtedly poses a great challenge to financial management, and offline financial management can no longer meet the needs of users. The business model or other ways for users to use money makes people turn their attention to online financial management. In this situation, the advantages of online financial management are more obvious, which makes more and more users adopt online management. In order to make amount management more convenient, people have taken many optimization measures for online financial management. With the development of networks brought by the economy, people are no longer satisfied with the way of financial management, but the mode of financial management has changed from offline to online, which reduces the restriction of the financial management area to a certain extent. For enterprise users, it is helpful to collect and share financial data through the network [1]. Compared with the previous offline financial management mode, online management introduces a computer system to provide users with personal financial management functions more conveniently [2]. The online financial management system can run in a collaborative computing environment between multiple users, that is, users and financial advisers, which means that personalized financial guidance can be brought to users [3]. Personalized finance is based on a collaborative computing environment between a user and a financial adviser, in which 
a coaching engine is capable of making appropriate financial advice based on the user's information for better management [4]. In addition, the various accounts used by the users concerned can be linked through rules provided by the personalized financial management system so that funds can be transferred between the accounts [5]. For the financial management system, it mainly includes the client of the application program, the graphical user interface, and the commercial network server for online financial transactions [6]. Financial transactions can be realized using computer systems, including computer assistance, corresponding data structures, and machines, and this is not only for a certain user but also for universal use [7]. With the rapid development of networking, the financial management of enterprises urgently needs to be changed accordingly. To a certain extent, China's Accounting Law and Accounting Standards for Enterprises provide a suitable legal environment for online finance, provide convenience for online financial management, and achieve the advantages of coordination, convergence, and remoteness [8]. The resource planning (ERP) accounting system used by enterprises provides accountants with the functions of establishing account numbers and applying for fees, which enables enterprise users or accountants to easily manage financial data [9]. The online financial management system not only facilitates centralized financial management by enterprises but also executes and manages transactions conducted by merchants on centralized electronic transactions (CET) websites and realizes unified management by entrusting amount data of multiple websites to the financial system [10]. Online finance can display electronic billing and payment functions in an authorized user interface [11]. When using computers to deal with financial problems, there is usually a user database and numerous account numbers, which are primary and secondary and are related to each other to verify the use of financial amounts and finally display the data centrally in the main account [12]. The efficient setting of the rules of the financial management system allows operations to be performed at different levels within the budget data structure [13]. To some extent, the online financial system may also execute portfolio-building data for the user, risk tolerance data showing the level of risk tolerance of the investor [14]. All these indicate that the online financial management mode will be continuously updated and optimized with the development of the network. At present, the online financial system has shown the characteristics of rich data sources, timely business processing, fast transmission speed, and comprehensive and faithful reflection [15].

In this article, the online financial management system is constructed based on the blockchain technology of the Internet of Things, complex network information transmission detection technology, and multiplexed information transmission technology and by constructing databases, financial information systems, and financial analysis systems. It is proved by testing that it can run normally and has advantages in reliability, simultaneity, and delay, that is, data transmission efficiency. It can be applied to the complex operating environment of enterprise users, and the system has certain optimization advantages in design.

\section{The Background and Design}

2.1. Impact of Internet of Things on Financial Management. At present, with the development of economic globalization, the offline financial management mode can no longer meet the needs of users. For both enterprises and individual users, financial management, as one of the important links, has been impacted greatly or slightly. With the rapid development of network information, the ways, contents, objects, and expected goals of financial management have changed. Online financial management forms have emerged in line with the development of the times, making people's lives more convenient, which also means that people's traditional lifestyles are changing.

In the traditional business model, as a supplier, in order to gain more profits and internal market share, it often adopts a large-scale way to manufacture products to achieve the purpose of profit. In today's Internet context, consumers' choice of products is no longer limited to the types of offline products. Due to the increase of selectivity, suppliers will correspondingly increase diversified products suitable for consumers' needs in order to retain the market. This diversity is designed for users; that is to say, in today's society, information has become one of the keys to enterprise competition and development.

Internet of Things is a ubiquitous network based on the Internet, which is different and related to the Internet, but its core is still the Internet technology. For enterprises, the data in the Internet of Things can be traded, and the big data analysis and calculation of financial management are much more valuable than the use of the Internet. The financial management of merchants based on the Internet of Things can realize the intelligent identification, positioning, tracking, monitoring, and management of goods so as to realize the clarity of financial data and facilitate management and regulation.

The financial management used by today's users is especially represented by merchants and enterprises. It is mostly conducted online; in other words, the Internet is indispensable for online financial management.

However, the Internet mostly reflects the push and sharing of online information and content, and its role in the financial management systems is limited. As the information carrier of the Internet, the IoT shows applicability to the online financial management system and causes changes in financial management mode.

2.2. Changes in Financial Management. The traditional financial management mode is scattered in accounting data, which makes the processing of financial data not timely enough, which easily leads to the wrong summary, and may lead to artificial wrong calculation of data in the verification process, which is also a major factor of the wrong summary. For now, adopting the online financial management mode based on the Internet of Things can greatly reduce the errors 
of accounting data and avoid the influence of human factors to a great extent. Under the background of rapid development of science and technology, market demand changes rapidly. Using network technology to process financial data and make timely adjustments according to needs can promote the benign development of enterprises or other individual users and improve security.

In addition, traditional financial management is mainly based on the purpose of maximizing benefits. Ignoring the potential value of customers, knowledge capital, society, etc., the financial management in the form of the Internet of Things can know the changes of customers' needs through the shared big data model so as to realize the output of products and enhance their own value, so the needs of customers have become a kind of orientation under the background of Internet of Things.

The traditional financial management process mainly manages the trend of funds, and the operation is relatively simple. Therefore, the lack of connection with the data needed by enterprises or other individual users may reduce practicability when users finally synthesize the data. The financial management under the influence of the Internet of Things needs to manage the funds and business information synchronously, and the expansion of the scope makes it more convenient and clear for users to use the data.

2.3. Design of Financial Management. With the development of social information technology, contemporary financial management has more and more advantages than handwritten registration, but its development is not limited to satisfaction. With the progress of technology, the needs of various user groups for financial management are becoming more and more detailed. Therefore, in order to meet the needs of users, the design of financial management system is particularly important.

First of all, the design of an online financial management system needs to be clear about the goals that need to be achieved. These goals will vary according to different user groups, but they can be roughly divided into the following aspects:

(1) The operation is simple; that is, the designed financial management system should reduce the complexity of the process when it is used so that it is suitable for users. This is mainly affected by the uneven ability level of users in society and the convenience of using them at work.

(2) Real-time control, that is, users can know and control financial information in time through the financial system.

(3) Clear rights and responsibilities, that is, the information of all personnel who have used the management system can be verified, that is, the situation of users and their use time.

(4) Security, that is, the scope of use of personnel authority should be the personnel within the scope of duty authority, and there is no right to operate the work that does not belong to the scope of duty.
(5) Support query, summary, printing, and other functions, that is, users can manage data from various aspects of the financial system.

Secondly, we should follow the principle of designing financial management system. For the design of the system, there are certain principles that can make it more standardized. A sound financial management system often follows the following principles:

(1) Practical, that is, the design of financial management system should be based on the actual application and meet the needs of users.

(2) Security, that is, the user's financial information should be in a safe environment. Security is the basis of the operation of the financial system, which is generally ensured by the cooperation of articles of association, layout, system, and technology.

(3) It is feasible; that is, the management system can be constructed through technology, safety performance and system.

Finally, users should determine a clear module division in order to facilitate flexible management, form a good standard, and achieve a better matching degree between the financial management system and the development of users, in which clear modules can be departments with a clear division of labor. And with the establishment of the financial system, we should also improve the information system and network security system. On the one hand, it can examine the personnel and usage of the financial system; on the other hand, it can also strengthen the management risk of financial data leakage. The perfection of the database can make the financial management refined so as to become the basis point for users to make relevant decisions, including costs, expenditures, existing capital, and other expenses.

Nowadays, the design of financial management system generally combines finance with business to clarify all aspects of user data, which can be referred to in Figure 1 for details.

From Figure 1, it is possible that the financial management system can be divided into seven modules, and the above functional modules can deeply analyze and apply the application technology of the system. In this article, blockchain technology and Internet of Things technology are proposed to achieve the above functions, which can get better application results.

\section{Related Technologies}

3.1. Blockchain Technology of Internet of Things. The setting of the online financial management system is mainly based on the Internet of Things, so it is important to explore the related technologies of the Internet of Things. Blockchain technology is widely used in data transmission, that is, data sharing, in the Internet of Things, which is mainly shared and stored through consensus nodes; that is to say, consensus nodes affect the decentralization degree of the blockchain network and then indirectly affect the operation of financial management. 


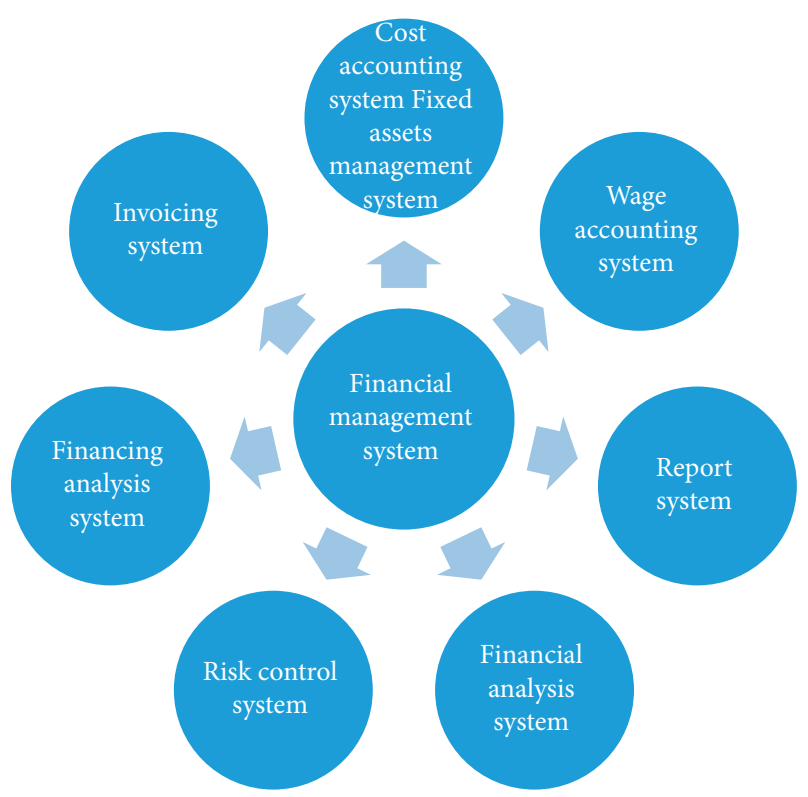

FIgure 1: Components of the financial management system.

Step 1: calculate the storage of users' financial data files in the consensus node of the blockchain. The formula is as follows:

$$
\Psi=\left[\begin{array}{cccc}
x_{1,1} & x_{1,2} & \cdots & x_{1,|F|} \\
x_{2,1} & x_{2,2} & \cdots & x_{2,|F|} \\
\vdots & & & \\
& \vdots & \ddots & \vdots \\
x_{|c|, 1} & x_{|c|, 2} & \cdots & x_{|c|,|F|}
\end{array}\right],
$$

where $F$ is the shared financial data file in the same consensus period, and $C$ is the consensus node.

The second step: calculate the number of data files for users as follows:

$$
\Psi_{i,|F|}=x_{i, 1}+x_{i, 2}+\cdots+x_{i,|F|},
$$

where $F$ is the step between user data.

Step 2: calculate the number of copies of the user's data file. The formula is as follows:

$$
\Psi_{|c|, j}=x_{1, j}+x_{2, j}+\cdots+x_{|c|, j} .
$$

Step 3: xalculate the variance as follows:

$$
\operatorname{var}=\frac{\sum\left[\Psi_{i,|F|}-\sum \sum x_{i, j} / N_{c}\right]^{2}}{N_{c}-1} .
$$

In the formula, the variance is the difference of data files stored in consensus nodes and var is variance value of original data.

Step 4: calculate the decentralization degree of the blockchain network. The formula is as follows:

$$
B=\frac{\beta_{1} F_{\text {con }}+\beta_{2} F_{\mathrm{ver}}}{\operatorname{var}}+k,
$$

where $k$ is the error parameter, $\beta_{1}$ and $\beta_{2}$ are the system parameters, and $F_{\text {con }} / F_{\text {ver }}$ is the frequency factor of different decentralized data.

Step 5: deal with the block propagation delay, and the formula is as follows:

$$
\tau_{\text {nor }}=\frac{\tau-\tau_{\text {mean }}}{\tau_{\max }-\tau_{\min }}
$$

where $\tau_{\max }$ is the maximum value of block propagation, $\tau_{\text {min }}$ is the minimum value of block propagation, and $\tau_{\text {mean }}$ is the average delay of system block propagation. Step 6: deal with the degree of decentralization. The formula is as follows:

$$
B_{\text {nor }}=\frac{B-B_{\text {mean }}}{B_{\text {max }}-B_{\text {min }}},
$$

where $B_{\max }$ is the maximum value of decentralization degree, $B_{\min }$ is the minimum value of decentralization degree, and $B_{\text {mean }}$ is the average value of decentralization degree.

3.2. Information Transmission Detection in Complex Networks. The design of complex network information transmission detection technology can improve the efficiency of data transmission. The important foundation of financial management using the Internet of Things is to effectively adjust the data nodes in the Internet of Things, which is the premise of efficient information transmission. Therefore, in order to relieve the pressure of financial system detection, it is very important to set a suitable algorithm to filter financial information.

Step 1: calculate the probability of more valuable data after false information filtering. The formula is as follows:

$$
p=1-\left(1-\frac{N}{L}\right)^{D}
$$

where $P$ is the probability, $L$ is the number of packets, and $D$ is the transmission speed.

Step 2: calculate the probability that false information packets can be filtered. The formula is as follows:

$$
p=1 \text { if } M=L
$$

where $M$ is the transmission rate.

3.3. Multiplexing Information Transmission Technology. Target selection, index selection, and scheme design are three steps of information transmission through the Internet of Things. The correlation matrix can be established through the three steps, and matrix A can be established from the values calculated by standards such as channel length, information integrity, and energy loss and transmission time. 


$$
A=\left[\begin{array}{cccc}
1 & 1 / 2 & 4 & 3 \\
2 & 1 & 7 & 5 \\
1 / 4 & 1 / 7 & 1 & 1 / 2 \\
1 / 3 & 1 / 5 & 4 & 3
\end{array}\right] .
$$

The respective evaluation matrices for channel length, information integrity, and energy loss and transmission time are as follows:

$$
\begin{aligned}
& B_{1}=\left[\begin{array}{ccc}
1 & 2 & 1 / 3 \\
1 / 2 & 1 & 2 \\
3 & 1 / 2 & 1
\end{array}\right], \\
& B_{2}=\left[\begin{array}{ccc}
1 & 1 / 3 & 1 / 8 \\
3 & 1 & 1 / 3 \\
8 & 3 & 1
\end{array}\right], \\
& B_{3}=\left[\begin{array}{ccc}
1 & 1 & 3 \\
1 & 1 & 3 \\
1 / 3 & 1 / 3 & 1
\end{array}\right], \\
& B_{4}=\left[\begin{array}{ccc}
1 & 3 & 4 \\
1 / 3 & 1 & 1 \\
1 / 4 & 1 & 1
\end{array}\right] .
\end{aligned}
$$

Calculate the eigenroot and eigenvector as follows:

$$
B W=\lambda_{\max } w_{i},
$$

where $\lambda_{\max }$ is the maximum eigenvalue of matrix $B, W$ is the normalized eigenvector, and $w_{i}$ is the component of $W$.

Calculate the energy consumed by network information as follows:

$$
\left\{\begin{array}{l}
E_{i}^{s}=\alpha I \\
E_{i}^{t}(P)=P T I
\end{array}\right.
$$

where $E_{i}^{s}$ is used to sense network information flow, $\alpha$ is used to sense Internet of Things information, $I$ is the distance of network information, $E_{i}^{t}$ is used to run network information, $P$ is the outgoing signal strength, and $T$ is the running time.

Calculate the channel power of the network information transmission model as follows:

$$
\left[h\left(d^{n}\right)\right]=[K]-\eta\left[\frac{d^{n}}{d_{o}}\right]-[\xi]-E_{t}^{s}-E_{l}^{t},
$$

where $K$ is a constant, $d_{0}$ is the contrast distance, $\eta$ is the consumption of information transmission lines, and $\xi$ is slow fading.

Calculate the normalized weighted credibility goal of total storage as follows:

$$
\mathrm{PI}=\frac{\sum_{i, j=1}^{n} E\left[C_{i j}\left(S_{i j}\right)\right]}{\sum_{i, j=1}^{n} C_{i j}(1)} .
$$

In the formula, PI is the normalized weighted credible target of total storage; $C_{i j}(1)$ is the storage.
Calculate the estimated value of the storage capacity in the range $I$ to $J$ of the network information transmission nodes, and the formula is as follows:

$$
E\left[C_{i j}\left(S_{i j}\right)\right]=\sum_{S_{i j} \in S_{i j}} C_{i j}\left(S_{i j}\right) \times p_{s i j},
$$

where $s_{i j}$ is the set of invariant states and $p_{S_{i j}}$ the possibility of invariant states $s_{i j}$.

Calculated $p_{S_{i j}}$ by the following formula:

$$
\left\{\begin{array}{l}
X_{i} \leftrightarrow P_{i}, \bar{X}_{i} \leftrightarrow q_{i}, \\
P_{s_{i j}}=\prod_{i \in X_{i}} P_{i} \prod_{i \in X_{i}} q_{i} .
\end{array}\right.
$$

Calculate the normalized weighted credibility goal of the maximum storage capacity of the network information transmission node, and the formula is as follows:

$$
\mathrm{PI}_{i j}=E \frac{\left[C_{i j}\left(S_{i j}\right)\right]}{C_{i j}(1)-\left[h\left(d^{n}\right)\right]} .
$$

Judge the time $v_{k}$ when the node runs the network information classification $D_{k(t)}$, the classification missing rate $L_{k(t)}$ and $w_{k(t)}$ the relationship between them, and the formula is as follows:

$$
\begin{aligned}
& D_{K(t)}=\left\{\begin{array}{l}
d_{k(t)}, W_{k(t)} \leq C_{K(t)}, \\
d_{k(t)} \times\left(W_{k(t)} \leq C_{K(t)}\right)^{\beta}, W_{k(t)}>C_{K(t)},
\end{array}\right. \\
& L_{K(t)}=\left\{\begin{array}{l}
l_{k(t)}, W_{k(t)} \leq C_{K(t)}, \\
l_{k(t)} \times\left(W_{k(t)} \leq C_{K(t)}\right)^{\beta}, W_{k(t)}>C_{K(t)} .
\end{array}\right.
\end{aligned}
$$

Calculate the operational reliability of network information flow, and the formula is as follows:

$$
\left\{R_{i j}(t)\right\}=\prod_{\nu k \in P_{i j}(t)}^{l} e^{-\gamma \times f k(t)}-\prod_{\nu k \in P_{i j}(t)}^{l} e^{-\gamma \times g k(t)},
$$

which indicates the $r$ interface association.

Calculate the reliability of the long-distance transmission of multiplexed information in the Internet of Things:

$$
\left\{\begin{array}{l}
\text { Delay_} R_{C}(t)=\text { Delay }_{-} R_{i j} \frac{(t)}{D_{k(t)}}, \\
\text { Loss_}_{-} R_{C}(t)=\text { Loss_ } R_{i j} \frac{(t)}{L_{k(t)}},
\end{array}\right.
$$

where Delay_ $R_{G(t)}$ and Loss_ $R_{G(t)}$ are information transmission time and classification missing rate.

To calculate the accuracy of trusted transmission of longdistance information, the formula is as follows:

$$
\text { MSE }=\sqrt{\left(\frac{1}{n}\right) \sum_{i=1}^{n}\left(t_{k}-y_{k}\right)^{2} .}
$$

In the formula, $t_{k}$ is the expected outgoing and $y_{k}$ is actual outgoing. 


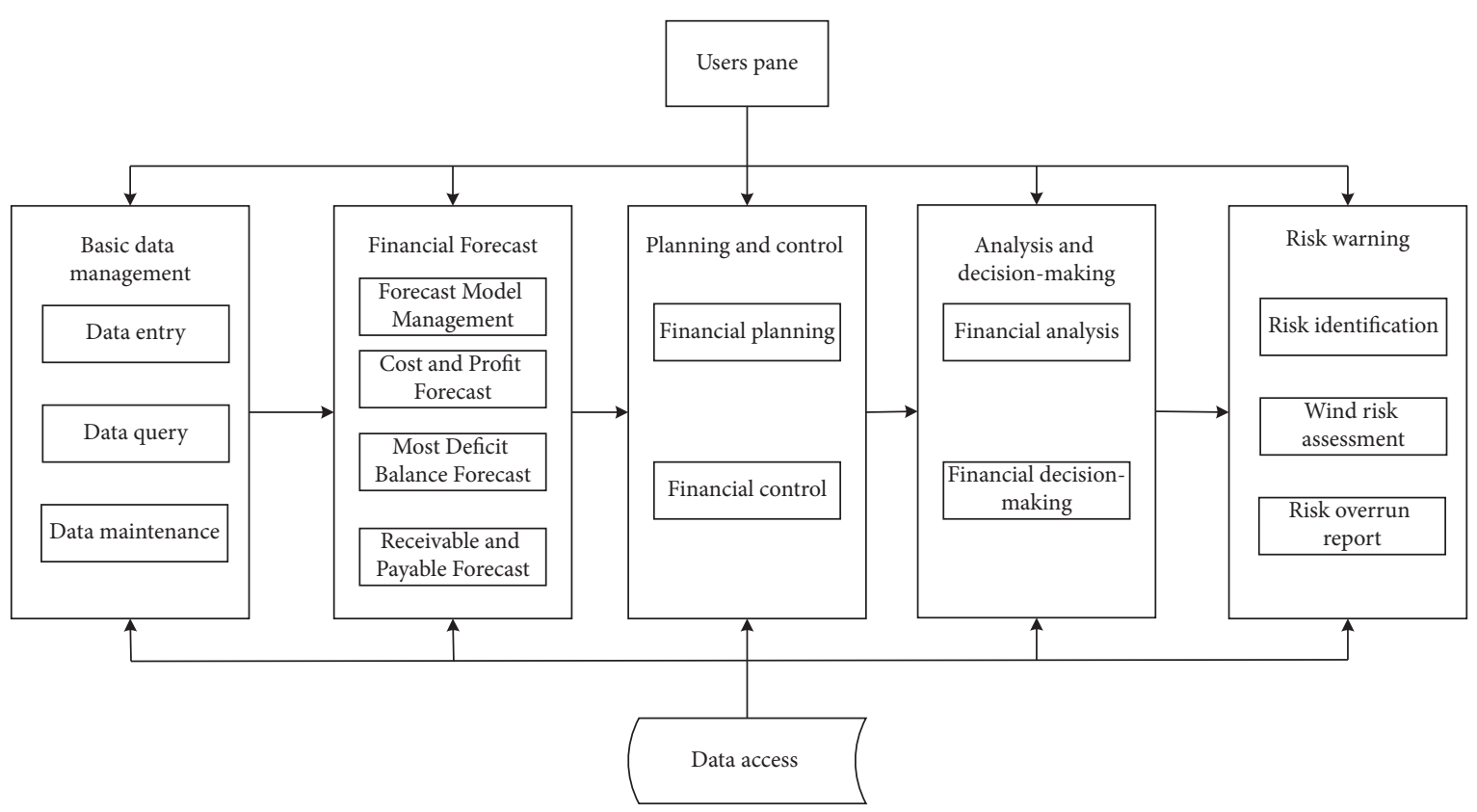

Figure 2: System software architecture.

\section{Online Financial Management System}

4.1. Specific Design. In this article, an online financial management system is constructed based on blockchain technology of the Internet of Things, complex network information transmission detection technology, and multiplexed information transmission technology. The system can be roughly divided into three layers, and the system architecture is shown in Figure 2. Through these three technologies, the interface between the server and the user can be realized, so that the information packet in the database can be transferred to the user window through the server. Because of the multichannel transmission technology, the influence of a large amount of information transmission and the transmission distance can be avoided, and the delay time can be shortened so that the user can obtain the financial data information in time. Based on the user window, users can operate on financial data, in which the user's request will be processed by the system and the results will be displayed. The business module covers the user's request and transmits the results to the user window through the comparison and adjustment of the database. The data access interface is also the interface for processing requests, that is, the part that extracts information from the database to get results.

Based on the framework of the financial management system software, physical data are built, which can be shown in Figure 3.

4.2. Major Systems. For online financial management system, financial information system and financial analysis system are particularly important, and business modules are mainly based on these two systems. Inventory management, general ledger, and report summary to constitute the financial information system are used to achieve the integrated management of business and finance, including wages, fixed assets, costs, and the generation of later reports. Inventory management is the statistical management of actual asset flow, such as purchasing goods, managing inventory, and selling products. A general ledger is the settlement of cost, salary, and fixed assets, which shows that the used financial data enter the payable and receivable system correspondingly so that the data can be comprehensively managed, while the report forms the financial data of the payable or receivable module into the report format to output the results.

The importance of a financial analysis system is reflected in the fact that the development of modern enterprises may be accompanied by financing. It is difficult to control risks in the investment process; doing a good job of financial analysis can provide users with a basis for decision-making so that the user's financial operation is healthier and more stable. At the same time, it can also analyze the financial situation, the income and risk of investment objectives, and the financing cost for users so that users can expand their customer scope and make timely adjustments according to their needs. The main processing flow of the financial information system and analysis system can be shown in Figures 4 and 5 .

The financial information system is mainly aimed at the normal application of financial information how to apply the system to achieve the role of management. The financial analysis system is aimed at the current financial data analysis, mainly with statistics and early warning functions, real-time analysis of financial information system data risks, and display.

4.3. Experimental Verification and Optimization. Based on the above design of an online financial management system, a more detailed system can be constructed. Based on this, the operation effect of the system can be tested to determine 


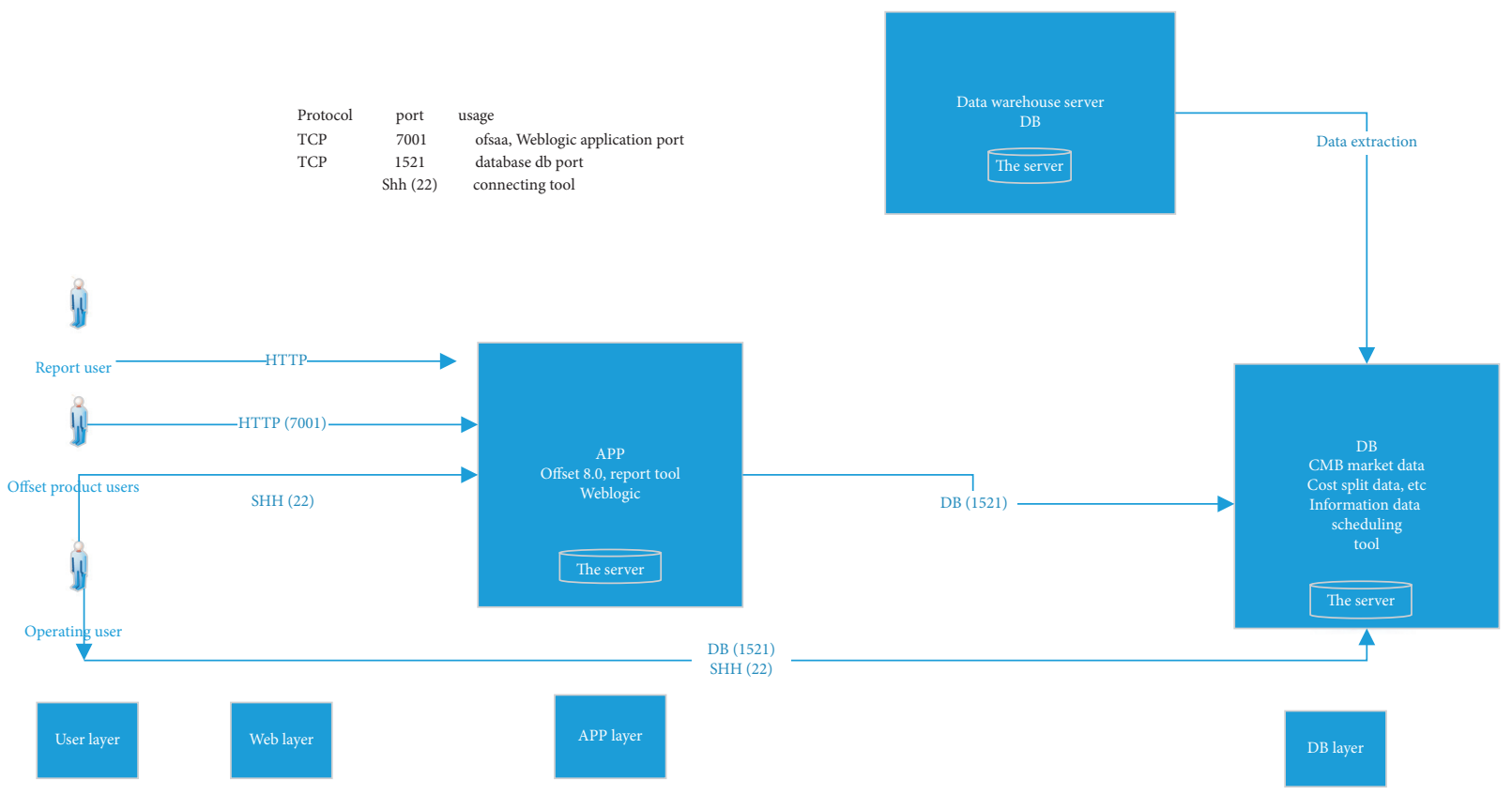

Figure 3: Physical construction diagram.

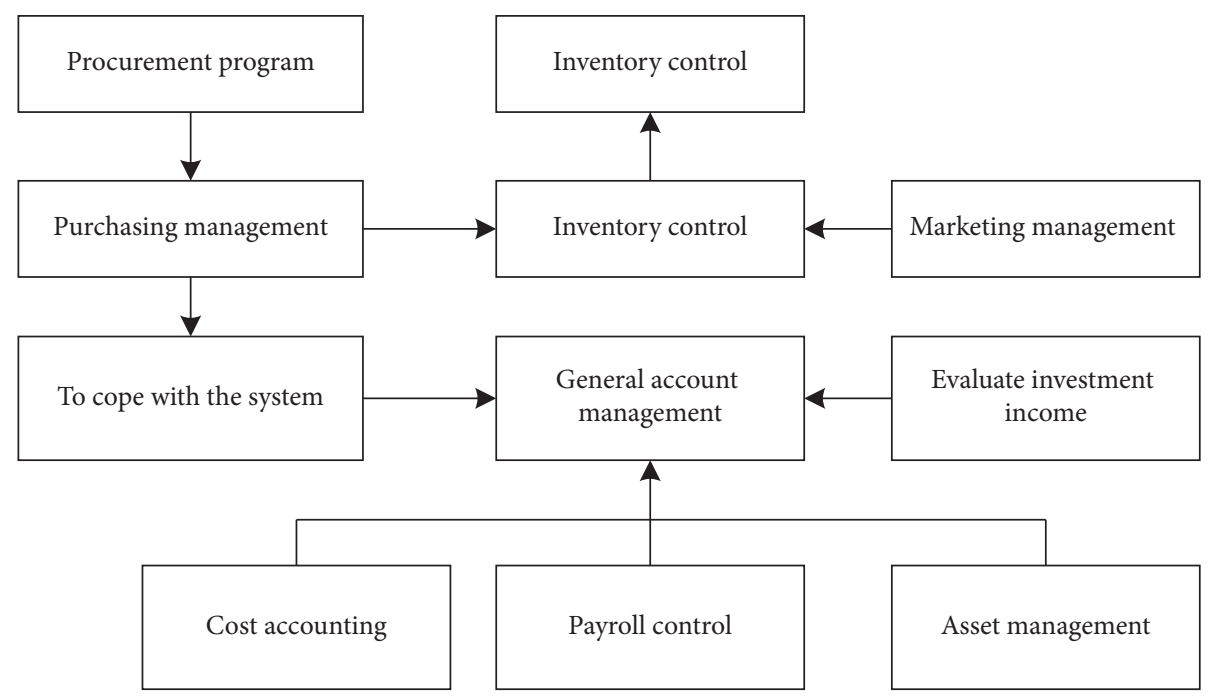

FIGURE 4: Financial information system.

whether its functions can run normally and whether the system has appropriate stability and accuracy can be observed. The specific testing contents include login account, financial management, inquiry, and functional normality, which can be shown in Table 1 .

Through the test of the operation effect in Table 1, it can be concluded that the online financial management system in this article can realize the functions required by users, achieve the purpose of integrating business and finance, and better meet the financial management requirements of users in actual use, which shows that the system has certain practicability. In addition, we still need to optimize compared with our predecessors. Otherwise, the proposed system construction does not have its advantages in adapting to scientific and technological progress; therefore, here, we need to make an optimization comparison. The system constructed in this article is compared with the system proposed by Zhang Yuzhuo earlier, which is suitable for the strategic integration development of his enterprise. After systematic comparative analysis, it can be found that this system is superior to its system in reliability, simultaneity, and delay, that is, data transmission efficiency, as shown in Table 2 and Figure 6.

In addition to the overall system comparison, in this article, the provided method and traditional methods are also compared in three aspects: round-trip delay, timeliness, 


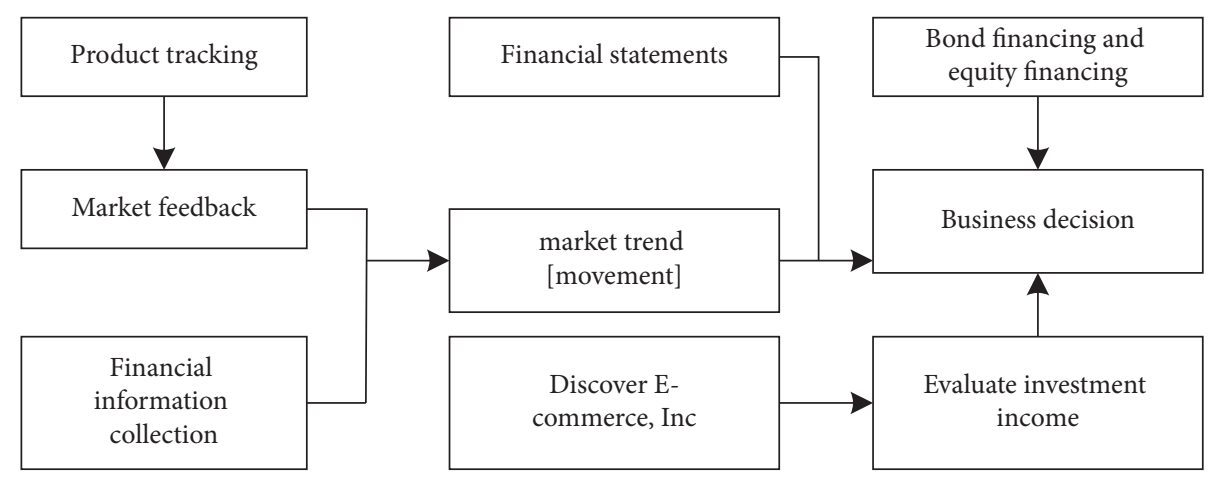

FIGURE 5: Financial analysis system.

TABLE 1: Running effect detection.

\begin{tabular}{|c|c|c|c|c|}
\hline Number & Test content & Test method & Expected results & $\begin{array}{l}\text { Test } \\
\text { effect }\end{array}$ \\
\hline 1 & Landing account & Enter a user name and password & $\begin{array}{l}\text { Username and password are correct; go to the } \\
\text { operation page }\end{array}$ & Yes \\
\hline 2 & $\begin{array}{c}\text { Financial } \\
\text { management }\end{array}$ & Permissions personnel operations & Accurate operational data & Yes \\
\hline 3 & Financial inquiry & Go to the operating module query & Query according to the conditions & Yes \\
\hline 4 & System function & Input the data, and make a statistical analysis & Displays the data results & Yes \\
\hline 5 & $\begin{array}{l}\text { Document } \\
\text { consistency }\end{array}$ & $\begin{array}{c}\text { Check that the document content is consistent } \\
\text { with the data }\end{array}$ & User documentation is consistent with the data & Yes \\
\hline 6 & $\begin{array}{l}\text { Document } \\
\text { correctness }\end{array}$ & Check the information for its accuracy & Ensure the user document is correct & Yes \\
\hline 7 & Data timeliness & Check the data transmission rate & Data appears in time during the operation & Yes \\
\hline 8 & Financial analysis & $\begin{array}{c}\text { Enter the relevant data to analyze the risk } \\
\text { nature }\end{array}$ & Error of the relevant data & Yes \\
\hline 9 & Financial accounting & $\begin{array}{l}\text { Enter the salary and other data accounting and } \\
\text { testing }\end{array}$ & Comprehensive data were obtained & Yes \\
\hline 10 & Data modification & Modify the data content & Cover the raw data after modifying the data & Yes \\
\hline 11 & $\begin{array}{l}\text { Information } \\
\text { registration }\end{array}$ & $\begin{array}{c}\text { Use the equipment personnel information to } \\
\text { record }\end{array}$ & The user records can be checked & Yes \\
\hline
\end{tabular}

TABLE 2: System comparison results.

\begin{tabular}{lccc}
\hline Indicators & Test index & Paper system & Zhang Yuzhuo system \\
\hline Reliability & Operation success rate & $99.53 \%$ & $99.13 \%$ \\
Simultaneity & Number of users & 275 & 250 \\
Delay & Page delay & 1.35 & 1.49 \\
Correctness & Operation delay & 1.92 & 2.13 \\
Reliability & Query delay & 2.50 & 2.89 \\
Simultaneity & Data accuracy & $99.76 \%$ & $99.53 \%$ \\
\hline
\end{tabular}

and average variance of information transmission. The comparison results are shown in Figures 7-10.

Firstly, the round-trip delay of information transmission is compared.

Moreover, the timeliness is compared.

The average variance of information transmission is compared.
Of course, the optimization of the system should not be limited to its internal construction. For users' financial management, it is extremely important to make an optimized goal, adjust the designed financial management system to adapt to the operation mechanism of users (enterprises), strengthen the specific management content, and strengthen financial prediction. 


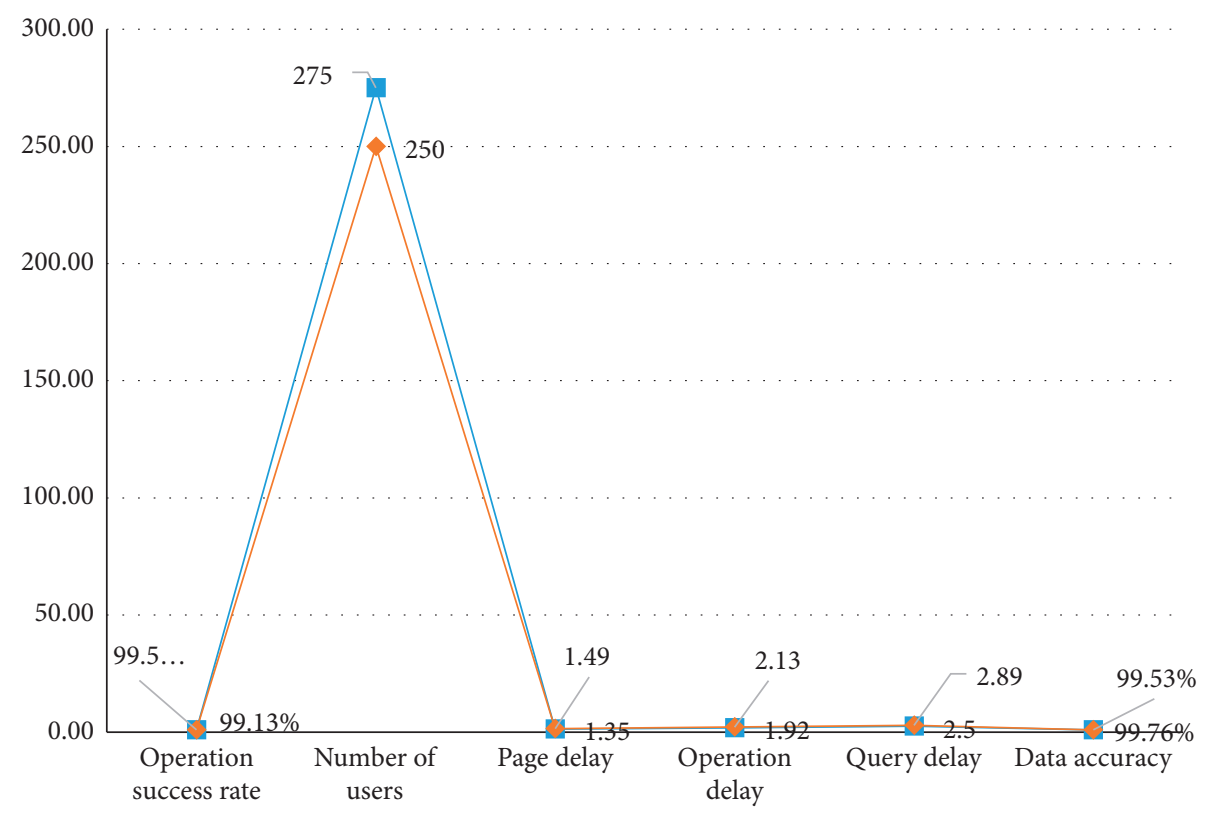

Paper system

$\_$Zhang Yuzhuo system

Figure 6: System comparison diagram.

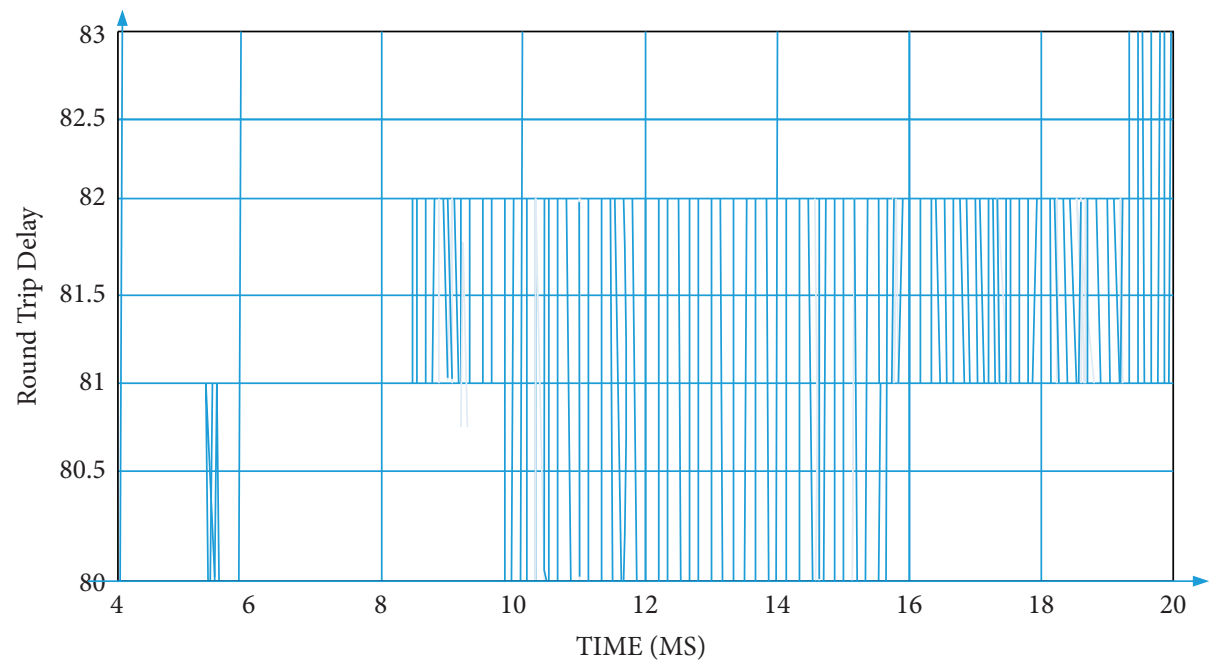

Figure 7: Conventional method.

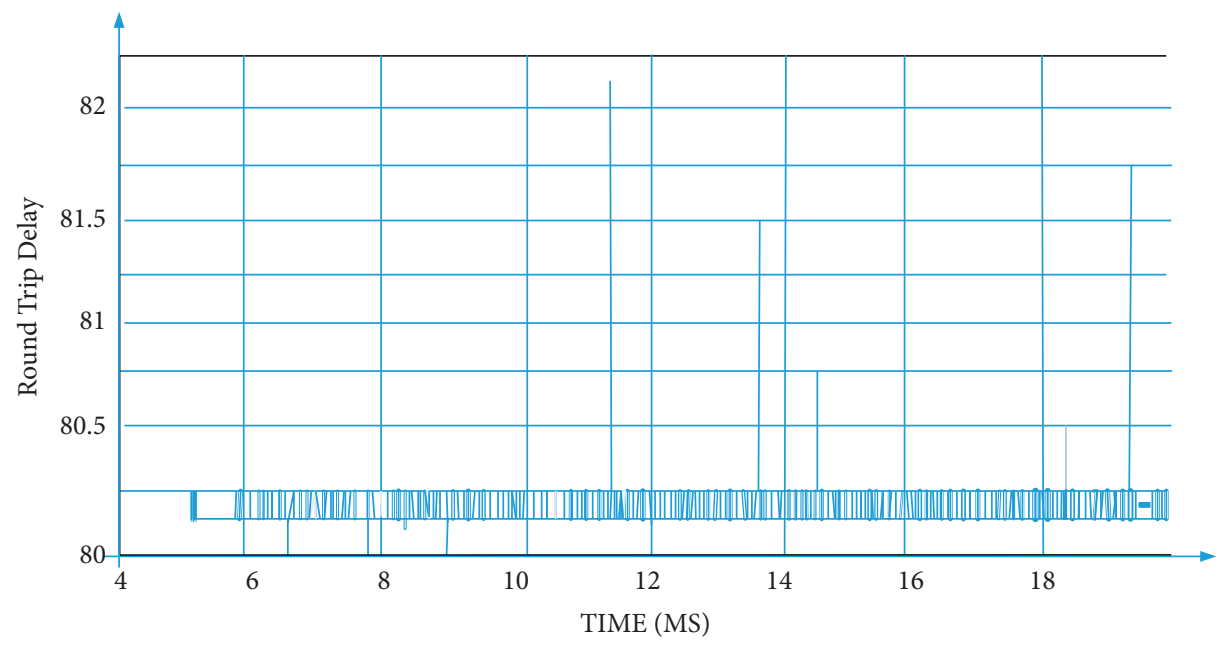

Figure 8: Method in this article. 


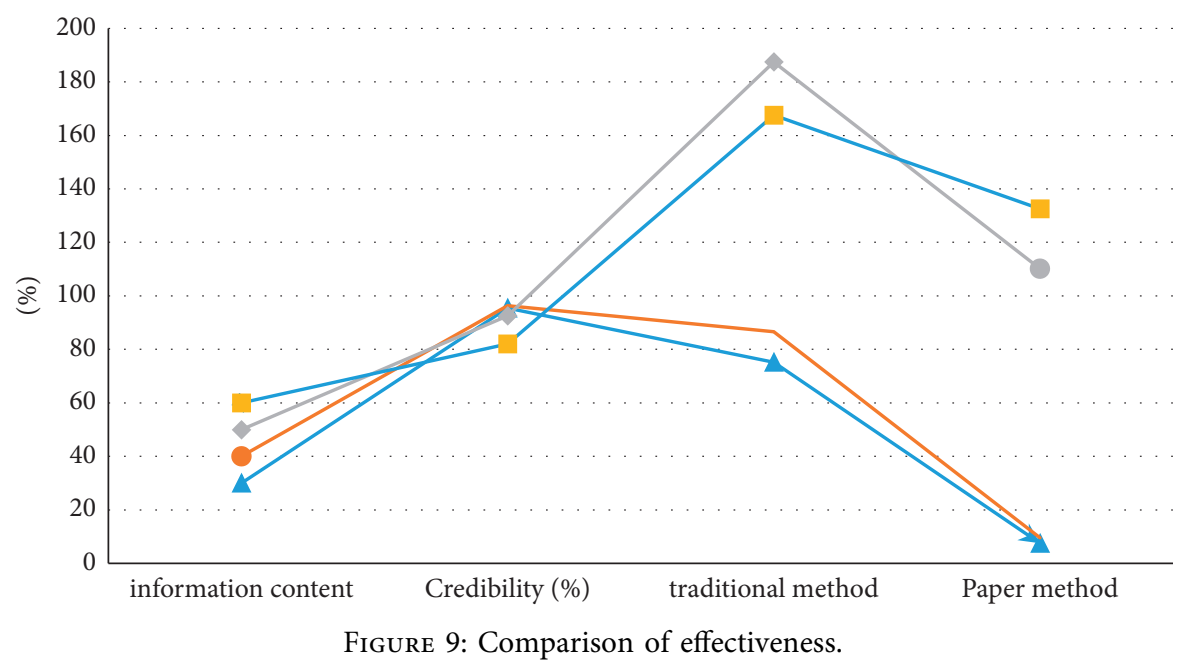

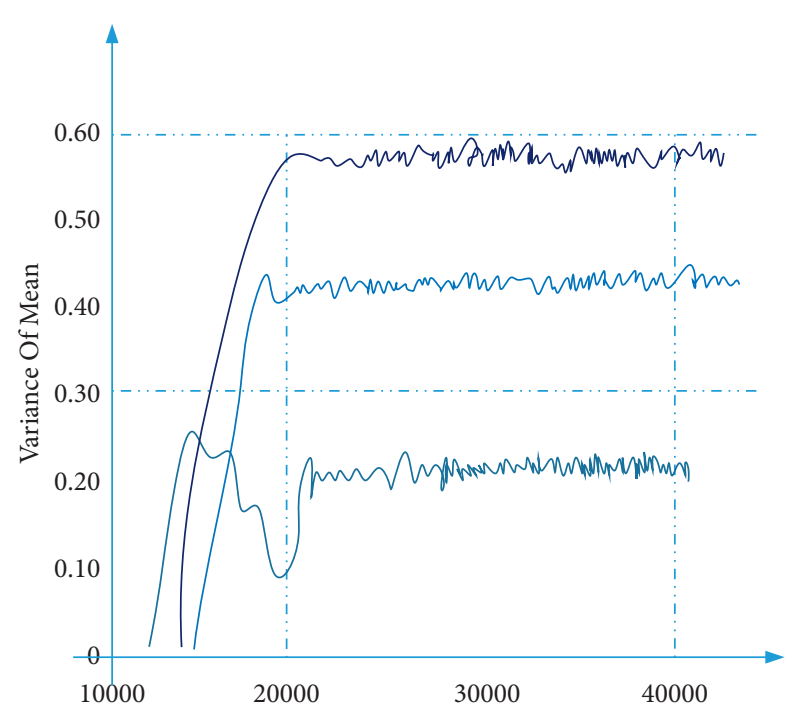

Figure 10: Comparison of mean variances.

\section{Conclusion}

In this article, blockchain technology of the Internet of Things, complex network information transmission detection technology, and multiplexing information transmission technology are adopted to promote the financial system to realize online data information summary and carry out accounting business. Different from the previous shortdistance database packet information transmission, the relatively long-distance transmission can be realized by adopting complex network information transmission detection technology and multiplex information transmission technology, which greatly reduces the difficulty of data summary and improves the timeliness of financial accounting and management for users. In addition, the establishment of a database, financial information systems, and financial analysis systems by users can make financial management more convenient and easy to view and greatly reduce the errors caused by human beings in the accounting process. With the rapid development of computer science and technology, financial management is not only satisfied with single business development, but enterprises will inevitably have mergers and financing. In this case, the existence of an analysis system is extremely important.

On the basis of designing the general framework of the online financial management system, this article explains the main parts, to a certain extent; the applicability of the online financial system is expanded; through comparison, it shows that it is relatively optimized, and the usability of the designed financial system is clear. Therefore, through the structural integration of financial management system and the assistance of database, financial information system, and financial analysis system, a complete financial system model is achieved, and the integration of user set business and finance is realized.

The system constructed in this article is compared with the system proposed by Zhang Yuzhuo earlier, which is suitable for the strategic integrated development of his enterprises. After a comparative analysis of the system, we can find that the system has advantages in reliability, simultaneity, and delay, that is, data transmission efficiency, which proves that it has been optimized relatively and is more suitable for the operation of financial management in the complex operating environment of users.

With the rapid development of science and technology, the use of financial systems is changing rapidly. For users, the design system that can meet their current needs is important. Therefore, we should design and optimize the financial system based on a realistic principle. As far as this study is concerned, the optimization degree is still relatively low, the expanded use level is relatively insufficient, and the construction in the early stage is still in a more complex degree, which limits the better complexity of online financial system to a certain extent. Next, there may be more suitable technologies for financial systems in the information technologies related to the Internet of Things. Therefore, timely use of relevant technologies or developing a new technology to build the system to help users better develop and improve the applicability of online financial management systems and reduce their shortcomings will be the direction of our continued efforts. 


\section{Data Availability}

The experimental data used to support the findings of this study are available from the corresponding author upon request.

\section{Conflicts of Interest}

The author declares that there are no conflicts of interest regarding this work.

\section{References}

[1] W. Lin and J. Chen, "Structure optimization of big data financial industry based on $5 \mathrm{G}$ network processor and embedded system," Microprocessors and Microsystems, vol. 82, 2021.

[2] W. Wang, "The perfection of the financial management system based on the computer network environment," $A u$ tomation \& Instrumentation, vol. 9, pp. 165-167, 2018.

[3] J. Ramakrishnan and A. Mahendran, "A framework and implementation of an online research management system," Indian Journal of Science and Technology, vol. 9, no. 48, 2016.

[4] X. Jia and J. Xu, "Internal control of accounting information system in regional chain technology," Journal of Physics: Conference Series, vol. 1617, no. 1, Article ID 012002, 2020.

[5] R. Zheng, "Applications research of blockchain technology in accounting system," Journal of Physics: Conference Series, vol. 1955, no. 1, 2021.

[6] Y. Zhang, "On the application of computer in the internal control of financial accounting system," Journal of Physics: Conference Series, vol. 1744, no. 4, Article ID 042066, 2021.

[7] R. L. Davis, "Marketing a sound financial management system," Medical Group Management, vol. 29, no. 3, pp. 60-65, 1982.

[8] X. Chen and X. Chen, "Research on the systematization of computer accounting information based on internal control," Journal of Physics: Conference Series, vol. 1648, no. 3, 2020.

[9] C. Long, "Study on online financing based upon Internet and E-commerce," International Journal of Business and Management, vol. 4, no. 8, 2009.

[10] M. K. Borstnar and A. Pucihar, "Impacts of the implementation of a project management information system-a case study of a small R\&D company," Organizacija, vol. 47, no. 1, pp. 14-23, 2014

[11] M. Kopel, C. Riegler, and G. Schneider, "Providing managerial accounting information in the presence of a supplier," $E$ ropean Accounting Review, vol. 29, no. 4, pp. 803-823, 2020.

[12] J. Shen and L. Han, "Design process optimization and profit calculation module development simulation analysis of financial accounting information system based on particle swarm optimization (PSO)," Information Systems and E-Business Management, vol. 18, no. 2, pp. 1289-1318, 2019.

[13] L. Vo Tan and H. N. Ngoc, "Exploring the impact of dynamic environment and CEO's psychology characteristics on using management accounting system," Cogent Business \& Management, vol. 7, no. 1, 2020.

[14] M. Assefa, Y. Jagannadha Rao, and A. Yohannes, "Designing of accounting information system for small and medium enterprises: application of PLS-SEM," International Journal of Sciences: Basic and Applied Research, vol. 54, no. 3, pp. 124-139, 2020, https://ssrn.com/abstract=3734436.

[15] I. Chukwuemeka, "Problems and prospects of auditing in a computerised accounting system," Journal of Emerging Trends in Economics and Management Sciences, vol. 10, no. 6, pp. 294-299, 2019, https://hdl.handle.net/10520/EJC-1cfa41 $38 \mathrm{a} 0$. 